\title{
Reflexiones en torno al concepto de integración en la sociología de la inmigración
}

\author{
Encarna Herrera \\ Universidad Nacional de Educación a Distancia. Centro asociado de Terrassa \\ Alcalde Perellada, 2, 08222 Terrassa (Barcelona). Spain
}

\section{Resumen}

Sin la pretensión de llevar a cabo una exposición representativa de las formulaciones de la perspectiva de la integración, se realiza una reflexión en torno a sus usos conceptuales. La «integración» de los inmigrantes es una cuestión planteada desde las diversas esferas en las sociedades de inmigración, como consecuencia de la presencia de aquéllos en el espacio social. Construir el tema en problemática o temática sociológica se realizaría a partir del análisis conjunto de la inmigración y de la sociedad de recepción, de la interacción que se crea entre ambos actores - -unmigrantes" y "autoctonos"- en el espacio de las sociedades de llegada.El análisis de la inmigración no puede ser llevado a cabo independientemente del análisis de las sociedades de Ilegada desde la globalidad de las relaciones sociales que las caracterizan.

Palabras clave: integración, inmigración, asimilación.

Abstract. Considerations on the concept of integration in the Sociology of Immigration

The article deals with the concept of integration of immigrants in the receiving society. The analysis of immigrations has to be done in relationship to the global social relations in this receiving society.

Key words: integration, immigration, assimitation.

\section{Sumario}

La sociología de la inmigración: construcción del objeto de estudio

En torno a los usos conceptuales de integración, asimilación, adaptación e inserción
En torno al concepto integración

Conclusión

El tema de las migraciones ha sido abundantemente tratado en la literatura sociológica, así como en la producción de otras ciencias sociales, y quisiera señalar aquí, con la dificultad que la limitación de este espacio supone, algunas tendencias en que se ha centralizado, en los últimos treinta años el tema 
de la sociología de la inmigración en Europa, enlazando una reflexión en torno a la construcción del objeto de estudio en esta área y en concreto con relación al tema de la uintegración» de los inmigrantes. No ha sido la intención realizar una exposición amplia y representativa de las diversas formulaciones de la perspectiva de la integración, sino, más bien, llevar a cabo una reflexión en torno a su utilización conceptual.

\section{La sociología de la inmigración: construcción del objeto de estudio}

Una tendencia en el estudio de las migraciones ha sido considerar el tema desde la perspectiva del país de acogida, del país de inmigración y no de los países de partida, o la combinación de ambos prismas en un conjunto. Se ha estudiado el fenómeno migratorio, por tanto, en relación con los problemas que se plantean en la sociedad receptora, sin prestar muchas veces atención a las cuestiones relativas a las causas de la inmigración ni a los orígenes de los inmigrantes. Diversos autores coinciden en ello, entre ellos A. Sayad y M. Morokvasic 1 en sus balances acerca de las contribuciones al tema, y una simple revisión de la literatura sobre las migraciones lo confirma.

Otra de las tendencias generales observadas es la centralización de los trabajos en el tema de la uintegración» de los inmigrantes en la llamada sociedad "receptora". La perspectiva de la integración a menudo corresponde a una visión asimilacionista que pone el acento en la adopción por los inmigrantes de las características culturales de la sociedad de inmigración.

También, una constante en los trabajos ha sido la inclinación a considerar la inmigración como problema social y no como problema sociológico ${ }^{2}$, tendiendo a tomar el objeto de estudio tal como es entendido por la sociedad, en el orden del sentido común, con frecuencia, sin realizar una conceptualización y una construcción científica del objeto de estudio.

En este sentido, Xabier Aierdi recuerda la precisión de Peter L. Berger cuando plantea el problema de desenmascarar las verdades oficiales que funcionan como interferencias en el análisis de la realidad social, siendo fundamental para ello la distinción entre problema social y problema sociologico: "El problema sociológico es siempre la comprensión de los factores que intervienen en este punto en términos de interacción social. $[\ldots]$ no consiste tanto en saber por qué algunas cosas "funcionan mal" desde el punto de vista de las autoridades y de la administración de la escena social, sino, en primer lugar, cómo fun-

1. Sayad, Abdelmalek (1984). «Tendances et Couranttes des Publications en Sciences Sociales sur l'Immigation en France depuis 1960m. Current Sociology, vol. 32, núm. 3, p. 217-304 y Morokvasic, Mirjana (1984). aMigration en Europe. Raport et rendancesn. Current Sociology, vol. 32, núm. 3, p. 1-40.

2. Esta visión es compartida por muchos especialistas en la materia, a modo de ejemplo: Sayad, Abdelmalek, íbidem, p. 249, y Aierdi, Xabier. "Inmigración y vida cotidiana en el Pats Vascon (ponencia presentada en el III Congreso Nacional de Sociología, San Sebastián, 1989). 
ciona todo el sisterna, qué conjeturas pueden extraerse de él y por qué medios se mantiene sin interrupción. $w^{3}$

A todo ello podríamos añadir las apreciaciones de A. Zehraoui, que pone el acento en torno a la teoría y la construcción epistemológica en los estudios sobre inmigración, seńalando la ausencia de marco teórico y de conceptualización en buena parte de ellos: "[...] se trata de un dominio no cuestionado donde los problemas han sido mal planteados. Cuestiones tan fundamentales como las relativas a la elección y construcción del objeto, a la distancia y la relación con el objeto, son inexistentes en algunas investigaciones y poco presentes en otras. Incluso existen pocas críticas y definiciones de las nociones utilizadas. Las categorias genéricas prevalecen sobre las categorías analíticas, las categorías institucionales e ideológicas sobre la denominación científica. ${ }^{4}$

Acertadamente señala A. Sayad que una de las dificultades que debe superar la sociología es la representación que se tiene comúnmente de la inmigración y del inmigrado en una sociedad dada, siendo el inmigrado del que se habla, el inmigrado tal como se ha constituido y determinado, un objeto del discurso común ${ }^{5}$. Es necesario preguntarse, en el fondo, sobre la naturaleza exacta de la problemática de la inmigración y sobre su verdadera significación, "[...] ¿se trata verdaderamente de problemas de la inmigración o, mejor, de problemas específicos de los inmigrados? $\mathrm{O}$, al contrario, $[\ldots]$ ¿no son, más bien, los problemas que plantea, en realidad la presencia permanente y más y más penetrante de los inmigrados en el seno de la sociedad y de la nación?"

En torno a los usos conceptuales de integración, asimilación, adaptación e inserción

Quisiera tealizar brevemente algunas precisiones en relación a los conceptos de asimilación, adaptación, integración e inserción y su uso en la sociología de la inmigración, para detenerme posteriormente en uno de ellos, el de integración.

En primer lugar, se podría decir que existe una gran diversidad de definiciones y que el uso y significado de estos conceptos varía de unos países a otros. Como señala M. Morokvasic, las tesis asimilacionistas fueron cuestionadas a partir de los años sesenta en Gran Bretaña y en Francia, países de Europa Occidental con tradición de inmigración exterior y con una abundante producción dedicada al tema, aunque están todavía presentes en la literatura alemana ${ }^{7}$. El asimilacionismo tiende a desaparecer a nivel europeo, aunque no es un fenómeno generalizado, pero el concepto de adaptación queda implantado

3. Cita de Berger, Peter L.(1979). Introdacción a la Soctologta. México, p. 58-59, incluida en Aierdi, Xabier, íbid.

4. Zehraoui, Ahsène (1992). "Catégories scientifiques et catégories du sens commun". Migration Societé, vol. IV, núm. 21, mayo-junio: 9-17, p. I0.

5. Sayad, A. Op. cit.

6. Sayad, A. Op. cir., p. 247.

7. Morokvasic, M. Op. cit. 
en todos los países ${ }^{8}$. Según Sayad, en la literatura francesa los términos que se suelen emplear más comúnmente son adaptación, desmarginalización, supresión de handicaps, inserción social, con exclusión de otros términos como asimilación, integración y aculturación, que tienen una historia más connotada"

En relación con esto, se estaría produciendo en la sociología de la inmigración, según Zehraoui, un deslizamiento desde la elaboración conceptual a una simple denominación y desde una crítica semántica a una verdadera "guerra de palabras". Así, según este autor "[...] Como es escabroso denominar la asimilación, incluso cuando ésta permanece presente en el espíritu y sirve de modelo y de referente en las representaciones y las políticas de ciertas fracciones ideológico-políticas, abordamos el de "inserción" e "integración", [...] Utilizados de manera genérica e intercambiable, sirven para designar toda clase de relaciones y de situaciones en los debates políticos y los análisis de los medios de comunicación, en el seno del mundo sindical, administrativo, en las prácticas de la acción social y en el medio asociativo. Cabría esperar más clarificación entre los sociólogos. No es así. Las definiciones abundan y los sentidos se multiplican.. ${ }^{10}$

En efecto, existe una gran diversidad de significados en cada uno de los conceptos mencionados -inserción, adaptación, integración, asimilación-, adoptándose uno u otro término en función de las preferencias de los autores, aunque en ocasiones se adoptan varios de ellos a la vez, como es el caso de $G$. Rocheau, para quien se produce una evolución, una sucesion temporal desde una primera etapa donde se daría una adaptación o una inserción, para pasar por una integración y llegar finalmente a la asimilación, que significa la pérdida de los elementos culturales del inmigrante, concepción en la que el factor tiempo sería fundamental ${ }^{11}$.

\section{En torno al concepto integración}

El término «integración", tiene una gran variabilidad semántica, con diversas acepciones, llevando a una cierta ambigüedad, ya que siendo utilizado comúnmente con distintos sentidos, muchas veces su significado queda implícito sin una definición previa. Es bastante frecuente que sirva para designar una política social a llevar a la práctica, y ha llegado a ser central en los debates políticos en todos los países de Europa.

Este concepto, según Michel Oriol, tiene dos grandes connotaciones: por un lado es un término que ha entrado en la lengua común; «integradow designa un conjunto de grupos de origen extranjero que no plantean problemas a la población autóctona, siendo un vocablo muy connotado por la noción de invisibili-

8. Morokvasic, M. Op. cit., p. 6.

9. Sayad, A. Op. cit.

10. Zehraoui, A.Op. cit., p. 13.

11. Rocheau, G. (1987). "Integration ou assimilation, migration et patience». Hommes et Migrations, núm. 1100 , febrero, p. 38-42, en Zehraoui, A. Op. cit., p. 14. 
dad ${ }^{12}$. Y, por otro lado, es utilizado también en el sentido de "igualdad formal» de los inmigrantes y sus descendientes en comparación con la población autóctona.

En este último sentido lo utiliza Costa-Lascoux ${ }^{13}$, para quien la igualdad formal de trato es la fase última de la integración, pero precisando que los inmigrantes se insertan en sociedades heterogéneas, a menudo conflictuales, a lo que hay que añadir las desigualdades sociales y la discriminación racial, que están actuando limitando la igualdad formal.

Michel Oriol considera la integración como una interacción de las prácticas individuales de los sujetos y de las medidas tomadas a la vez por el país receptor y de partida. Abriéndose, así, una tipología de posibles respuestas o situaciones en función de si la sociedad de acogida favorece o no el pluralismo y si la sociedad de partida refuerza o no ka identidad cultural de los inmigrantes, respuestas que van desde la asimilación rápida a la afirmación identitaria de la cultura de origen ${ }^{14}$.

Existen algunas aportaciones que suscribirían la falta de delimitación entre la perspectiva de la integración y un enfoque conflictual, entre las que pueden mencionarse las de Lapeyronnie y Jazouli. Este último considera que la integración social y política de los jóvenes descendientes de la inmigración magrebí en Francia, que viven una experiencia de exclusión social, segregación y racismo cotidiano, solamente puede ser conflictual ${ }^{15}$. Mientras que Lapeyronnie partiendo de la hipótesis del asimilacionismo trata de explicar la formación de la acción y la movilización colectiva en los jóvenes descendientes de la inmigración magrebí en Francia, situando entre los factores internos de la movilización la constitución de una identidad colectiva entre estos jovenes y una estructuración de la colectividad a partir de redes asociarivas ${ }^{16}$.

En cierta manera, las ciencias sociales no tienden más que a dividir las prácticas de los grupos de origen extranjero en función de dos polos: separación/integración (lo que invoca a un recorrido progresivo desde fuera hacia adentro pasando por diferentes etapas, en el que se pueden dar paradas definitivas, es decir, formas de integración parciales), correspondiendo esta bipolaridad, según Oriol, no a una observación de los hechos sino a las categorizaciones del sentido común ${ }^{17}$.

12. Cita de Oriol, Michel, incluida en Campani, G. y Catani, M. (1985). «Les résaux associatifs italiens en France et les jeunes". Revue Europeenne des Migrations Internationales, vol. 1, núm. 2. diciembre, 143-159, p. 144.

13. Estas concepciones de Cosra Lascoux están tomadas de: Charbit, Yves (1988). «L'inregration des jeunes d'origine immigrée en Europe: bilan et perspectives". Revue Européenne des Migrations Internationales, vol. 4, núm. 3, 147- 152.

14. Charbit, Y. Op. cit.

15. Jazouli, Adil (1986). "Racisme et antiracisme dans l'action collective des jeunes maghrébins en France». Connexions, núm. 48.

16. Lapeyronnie, Didier (1987), Assimilation, mobilisation et action collective chez les jeunes de la seconde génération de l'immigration maghrebine». Revue Française de Sociologie $X X Y I I$, p. 287-318.

17. Oriol, Michel (1985). uL'ordre des identités". Revne Europeenne des Migrations Internationales, vol. 1, núm. 2, diciembre, p. 171-185. 
Finalmente, A. Bastenier y F. Dassetto realizan una fructífera aportación Ilamando la atención sobre la importancia del espacio y el tiempo en el fenómeno migratorio, proponiendo el concepto de "ciclo migratorio" como útil analítico del proceso de integración y de citoyenisation de los inmigrados. La integración sería un proceso de gran complejidad que entienden en términos de acción colectiva, englobando como actores los "viejos nacionales" y los "recién Ilegados", que negocian su copresencia en el espacio público. La inclusión o englobement de la inmigración en las sociedades europeas es un complejo proceso con una dinámica histórica que se desarrolla a través de un ciclo migratorio con diferentes etapas. "La dimensión temporal que introduce este concepto (el ciclo migratorio) trata de identificar los momentos estratégicos del proceso de interacción conflictual y con resultado incierto que se establece en el espacio público entre los "establecidos" y "los entrantes" en una sociedad dada ${ }^{18}$. Este proceso puede incidir en la dinámica social de la construcción de las sociedades afectadas por la inmigración. Según estos aurores, la cuestión de la integración de los inmigrantes se convierte así en la cuestión de la integración de las sociedades estatal-nacionales, sociedades industriales diversifcadas y complejas, que están a la búsqueda de nuevos principios integradores. El análisis de la inmigración no puede ser llevado a cabo independientemente del análisis de las sociedades de llegada desde la globalidad de las relaciones sociales que las caracterizan.

\section{Conclusión}

Para finalizar esta reflexión en torno al tema que nos ocupa, podríamos decir que la integración de los inmigrantes es una cuestión planteada como problema desde las diversas esferas en las sociedades de inmigración, como consecuencia de la presencia de aquéllos en el espacio social. Y que desde la sociología habría que ir más allá haciendo un esfuerzo de conceptualización construyendo el tema en problemática o temática sociológica. En este sentido, un camino sería el análisis conjunto de la inmigración y de la sociedad de recepción, del discurso por parte de ésta sobre el inmigrado y la inmigración y de los mecanismos de inclusión/exclusión ${ }^{19}$ que establece con respecto a los inmigrantes, en suma, de la interacción que se crea entre ambos actores — «inmigrantes" $y$ "autóctonos"- en el espacio de las sociedades de llegada.

18. Bastenier, Albert y Dassetto, Felice (1993). Immigration et Espace Public. La controverse de lintégration. París: Ciemi L'Harmattan, p. 10.

19. He tomado los conceptos de mecanismos de inclusión y exclusión de Bovenkerk, Frank; Miles, Robert y Verbunt, Gilles (1990), «Racism, Migration and State in Western Europe: A Case for Comparative Analysis». International Sociology, vol. 5, num. 4, diciembre. 